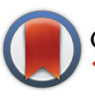

CrossMark \& click for updates

Cite this: Food Funct., 2016, 7, 1390

Received 9th December 2015 Accepted 18th January 2016

DOI: $10.1039 / c 5 f o 01525 a$

www.rsc.org/foodfunction

\section{Redox chemistry of the molecular interactions between tea catechins and human serum proteins under simulated hyperglycemic conditions}

\begin{abstract}
Hazal Özyurt, ${ }^{\mathrm{a}}$ Carolina Luna ${ }^{\mathrm{b}}$ and Mario Estévez ${ }^{{ }^{\mathrm{c}}}$
Carbonylation is an irreversible modification in oxidized proteins that has been directly related to a number of health disorders including Type 2 diabetes. Dietary antioxidants have been proposed to counteract the oxidative stress occurring under hyperglycemic conditions. An understanding of the nature and consequences of the molecular interactions between phytochemicals and human plasma proteins is of utmost scientific interest. Three tea catechins namely epicatechin (EC), epigallocatechin (EGC) and epigallocatechin-3-gallate (EGCG) were tested for (i) their affinity to bind to human serum albumin (HSA) and human hemoglobin $(\mathrm{HH})$ and (ii) their ability to inhibit tryptophan (Trp) depletion and for the formation of specific protein carbonyls and pentosidine in the aforementioned proteins. Both proteins $\left(20 \mathrm{mg} \mathrm{mL}^{-1}\right.$ ) were allowed to react with postprandial plasmatic concentrations of the catechins (EC: $0.7 \mu M, E G C$ : $1.8 \mu \mathrm{M}$, and EGCG: $0.7 \mu \mathrm{M}$ ) under simulated hyperglycemic conditions (12 mM glucose/0.2 mM Fe $\mathrm{me}^{3+}$ / $37^{\circ} \mathrm{C} / 10$ days). The three catechins were able to inhibit Trp oxidation and protein carbonylation in both plasma proteins. Some anti-glycation properties were linked to their binding affinities. The molecular interactions reported in the present study may explain the alleged beneficial effects of tea catechins against the redox impairment linked to hyperglycemic conditions.
\end{abstract}

\section{Introduction}

Protein oxidative modifications are a major class of protein post-translational changes and contribute to cell dysfunction and human disease. ${ }^{1,2}$ Carbonylation is an irreversible modification in oxidized proteins that has been directly related to a number of health disorders. ${ }^{3}$ Carbonyls can be formed in proteins by three different pathways: (i) radical-mediated oxidation of the side chains of alkaline amino acids such as lysine, threonine, arginine and proline; (ii) the reaction of the $\delta$-amino group of an alkaline amino acid with reducing sugars or their oxidation products and (iii) the oxidative cleavage of the peptide backbone via the $\alpha$-amidation pathway or the oxidation of glutamyl side chains. ${ }^{4}$ Among the three mechanisms, the Maillard-mediated reaction has been reported to be a significant carbonylation pathway in muscle and plasma proteins. ${ }^{5,6}$

The Maillard reaction occurs between amino groups in proteins and a reducing sugar such as glucose and leads to the

\footnotetext{
${ }^{a}$ Graduate School of Natural and Applied Sciences, Food Engineering Branch, Ege University, 35100 Izmir, Turkey

${ }^{b}$ Sistema Extremeño de Salud, SES, Cáceres, Gobex, Spain

${ }^{c} I P R O C A R$ Research Institute, TECAL research group, University of Extremadura,

10003 Caceres, Spain. E-mail: mariovet@unex.es; Fax: +34927257110
}

formation of multiple products including Schiff bases, Amadori products and advanced glycation end products (AGEs). ${ }^{7}$ The discovery that specific markers of oxidative stress such as protein carbonyls, $\alpha$-aminoadipic semialdehyde and $\gamma$-glutamic semialdehyde (AAS and GGS, respectively) are also formed in the presence of reducing sugars ${ }^{5,6}$ exemplifies the interconnections between protein glycation and protein oxidation already highlighted by Wolff et al. ${ }^{8}$ Akagawa et al. ${ }^{9}$ identified the Maillard reaction as responsible for the accumulation of AAS and GGS in plasma proteins from diabetic rats. The detection of post-translational changes in plasma proteins as a result of pathological conditions by using such specific markers is of indisputable interest for diagnosis and health control purposes. Carbonylation in particular is known to occur in plasma proteins of Type II diabetic patients with this oxidative damage being the cause of subsequent functional impairments. ${ }^{3,10}$ Little is known, however, about the formation of these particular protein carbonyls in human proteins under physiological and/or pathological conditions and the suitability of using these compounds as specific markers of glycosylation and disease.

Polyphenols have been attributed with diverse bioactivities as they act as free radical scavengers, metal chelators, enzymatic activity modulators, signal transductors and gene expression activators. ${ }^{11}$ Owing to their versatile biological func- 
tions, these compounds have been proposed for the treatment of chronic disorders, such as Type II diabetes, heart diseases and various types of cancer. ${ }^{11}$ Tea is an excellent source of polyphenols with (-)-epicatechin (EC), (-)-epicatechin gallate (ECG), (-)-epigallocatechin (EGC), and (-)-epigallocatechin-3gallate (EGCG) being the most abundant. ${ }^{12}$ These species have displayed many pharmacological effects such as antimutagenic, antiproliferative, anticarcinogenic and neuroprotective activities. ${ }^{13}$ Interestingly, EC, EGC and EGCG occur in the blood of human individuals after tea consumption at concentrations ranging from 78 to $550 \mathrm{ng} \mathrm{mL}^{-1} \cdot{ }^{14,15}$ While the binding affinities and molecular interactions between tea polyphenols and plasma proteins have been studied, ${ }^{16,17}$ the effects of these phytochemicals against the damage caused by oxidative stress and glycosylation to human proteins are mostly unknown.

The objective of this study was to evaluate the effectiveness of the three major tea polyphenols, namely EC, EGC and EGCG, against the carbonylation of human plasma proteins (human serum albumin and hemoglobin) under simulated pathological concentrations of glucose.

\section{Material and methods}

\subsection{Chemicals}

EGCG and EGC were purchased from HWI Analytik GMBH (Rülzheim, Germany). EC, albumin from human serum (HSA), human hemoglobin (HH), sodium cyanoborohydride $\left(\mathrm{NaCNBH}_{3}\right)$, diethylenetriaminepentaacetic acid (DTPA), 1,1-diphenyl-2-picrylhydrazyl (DPPH), sodium dodecyl sulfate (SDS), 4-aminobenzoic acid (ABA), 2-( $N$-morpholino)ethanesulfonic acid (MES) monohydrate and iron(III) chloride reagent grade were acquired from Sigma-Aldrich Co. Ltd (Steinheim, Germany). D(+)-Glucose monohydrate, sodium dihydrogen phosphate $\left(\mathrm{NaH}_{2} \mathrm{PO}_{4}\right)$, di-sodium hydrogen phosphate $\left(\mathrm{Na}_{2} \mathrm{HPO}_{4}\right)$, trichloroacetic acid (TCA), sodium acetate anhydrous, methanol, acetonitrile, diethylether, ethanol and hydrochloric acid were obtained from Scharlau Labs S.L. (Barcelona, Spain). Water used was purified by passage through a Milli-Q system (Millipore Corp., Bedford, MA). Solutions were freshly prepared prior to use.

\subsection{Assay of binding affinity between human plasma proteins and catechins}

For a detailed study of catechin-protein interactions, the quenching of protein intrinsic (tryptophan) fluorescence by the phenolics was employed as follows. HSA and $\mathrm{HH}$ $\left(20 \mathrm{mg} \mathrm{mL}{ }^{-1}\right.$ ) were dissolved in sodium phosphate buffer ( $\mathrm{pH} 7.4 ; 100 \mathrm{mM}$ ). Individual phenolics (EC, EGC, EGCG) were dissolved in aqueous methanol $(20 \%)$ in order to yield $0.87 \mathrm{mM}, 1 \mathrm{mM}, 1.3 \mathrm{mM}$ stock solutions, respectively. Fluorescence spectra were recorded on a Perkin Elmer LS 55 luminescence spectrometer (Perkin Elmer, Cambridge, UK) using a $10 \mathrm{~mm}$ quartz Suprasil fluorescence cuvette (Hellma, Germany). In order to quantify the potential interaction between catechins and human proteins, the latter were titrated in a cuvette by successive additions of individual catechin solutions (EC, 0.7-5.6 $\mu \mathrm{M}$; EGC, 1.8-14.4 $\mu \mathrm{M}$; EGCG, 0.7-5.6 $\mu \mathrm{M}$; final concentrations). This range of concentrations was selected based on the data available in the literature ${ }^{14,15}$ and on preliminary trials aimed to perceive the detectable quenching of trp fluorescence in the selected proteins. Fluorescence emission spectra were recorded from 300 to $400 \mathrm{~nm}$ with excitation at $280 \mathrm{~nm}$. The excitation and emission slits were both set to $10 \mathrm{~nm}$ and the scanning speed was $500 \mathrm{~nm} \mathrm{~min}{ }^{-1}$. All experiments were carried out at $37^{\circ} \mathrm{C}$. Fluorescence intensity was read at a protein emission maximum of $335 \mathrm{~nm}$. Fluorescence spectra of individual catechins at equal concentrations were recorded as blanks under the same experimental conditions and subtracted from the corresponding sample to correct the fluorescence background. The bimolecular quenching rate constant $\left(K_{\mathrm{q}}\right)$ was calculated using the Stern-Volmer equation $^{18}$

$$
F_{0} / F=1+K_{\mathrm{q}} \tau_{0}[\mathrm{Q}]
$$

where $F_{0}$ and $F$ are the fluorescence intensities of the protein solutions in the absence and presence of the quencher, respectively; $[\mathrm{Q}]$ is the quencher concentration, and $\tau_{0} \approx 5 \times$ $10^{9} \mathrm{~s}$ ) is the lifetime of the fluorophore in the absence of the quencher. ${ }^{18}$

The apparent binding constants $\left(K_{\mathrm{b}}\right)$ were calculated using the following equation: ${ }^{19}$

$$
\log \left(F_{0}-F\right) / F=n \log K_{\mathrm{b}}-n \log \left(1 /\left([\mathrm{Q}] F_{0}-F[\mathrm{P}] / F_{0}\right)\right)
$$

where $[\mathrm{P}]$ is the total protein concentration and $n$ the number of binding sites.

\subsection{DPPH radical scavenging activity}

Catechins (EC: $0.7 \mu \mathrm{M}$, EGC: $1.8 \mu \mathrm{M}$, and EGCG: $0.7 \mu \mathrm{M}$; final concentrations) were mixed with HSA $\left(20 \mathrm{mg} \mathrm{mL}^{-1}\right)$ and $\mathrm{HH}$ $\left(20 \mathrm{mg} \mathrm{mL}{ }^{-1}\right)$ solutions to obtain 11 different experimental units including the units from the total factorial design (3 catechins $\times 2$ human proteins) and their respective controls (containing each of these 5 components alone). Antioxidant activities of the above samples were measured against the DPPH free radical assay. Fifty $\mu \mathrm{L}$ of each sample was added to $2 \mathrm{~mL}$ of DPPH solution $\left(6 \times 10^{5} \mathrm{M}\right.$ in methanol). The decrease in absorbance at $517 \mathrm{~nm}$ was measured after $30 \mathrm{~min}$. The DPPH radical scavenging activity was calculated using the following formula:

$$
\begin{aligned}
& \text { DPPH radical scavenging activity }(\%) \\
& \quad=\left(1-A_{\text {control }} / A_{\text {sample }}\right) \times 100
\end{aligned}
$$

where $A_{\text {control }}$ is the absorbance of the control (containing all reagents except the sample), and $A_{\text {sample }}$ is the absorbance of the samples, both measured at $517 \mathrm{~nm}$.

\subsection{Experimental setting for glycosylation assay}

Three different types of reaction units containing each of the human protein solutions $\left(20 \mathrm{mg} \mathrm{mL}^{-1}\right)$ were prepared as follows: Reaction 1 included only the human proteins ( $\mathrm{HH}$ or 
HSA) as negative control samples (2 reaction units in total); Reaction 2 included $\mathrm{HH}$ or $\mathrm{HSA}, \mathrm{FeCl}_{3}(0.2 \mathrm{mM})$ and glucose (12 $\mathrm{mM}$ ) as positive control samples (2 reaction units in total); Reaction 3 included $\mathrm{HH}$ or $\mathrm{HSA}, \mathrm{FeCl}_{3}(0.2 \mathrm{mM})$, glucose $(12 \mathrm{mM})$ and each of the tea phenolics under study $(0.7 \mu \mathrm{M}$, EGCG; $0.7 \mu \mathrm{M}, \mathrm{EC} ; 1.8 \mu \mathrm{M}$ EGC; final concentrations) (6 reaction units in total). All reaction mixtures were prepared in triplicate $(10 \times 3=30$ in total $)$ and incubated at $37^{\circ} \mathrm{C}$ for 10 days with constant stirring. Samples were taken at fixed times (0, 3, 6, 10 days) for Reactions 1 and 2 and subsequently analyzed for tryptophan (Trp), AGEs and specific protein carbonyls. For Reaction 3, a single sampling was performed after 10 days of incubation for the analysis of trp, AGEs and specific protein carbonyls.

\subsection{Tryptophan measurements}

The concentration of Trp in human protein systems was measured on a Perkin Elmer LS 55 luminescence spectrometer (Perkin Elmer, Cambridge, UK). Human protein solutions were diluted with $100 \mathrm{mM}$ sodium phosphate buffer, $\mathrm{pH}$ 7.4. The emission spectra were recorded from 300 to $400 \mathrm{~nm}$ with the excitation wavelength established at $283 \mathrm{~nm}$. Excitation and emission slit widths were set at $10 \mathrm{~nm}$. The Trp content was calculated from the corresponding standard curves of HSA and HH. Emission spectra of the sodium phosphate buffer and the catechins were recorded under the same conditions and used as background spectra in the pertinent samples. The fluorescent quenching of catechins as measured in the experiment described in section 2.2. was also taken into consideration for accurate quantification purposes. Results are expressed as mM trp.

\subsection{Pentosidine measurements}

Pentosidine was analyzed using a LS-55 Perkin-Elmer fluorescence spectrometer (Perkin-Elmer, Beaconsfield, U.K.). Prior to the analysis, human protein solutions were diluted with $100 \mathrm{mM}$ sodium phosphate buffer, $\mathrm{pH}$ 7.4. Pentosidine was excited at $370 \mathrm{~nm}$, and the emitted fluorescence was recorded from 400 to $500 \mathrm{~nm}$. The excitation and emission slits were both set to $10 \mathrm{~nm}$ and the scanning speed was $500 \mathrm{~nm} \mathrm{~min}{ }^{-1}$. Results are expressed as fluorescence intensity (area units).

\subsection{Synthesis of AAS and GGS standard compounds}

$N$-Acetyl-L-AAS and $N$-acetyl-L-GGS were synthesized from $N \alpha$ acetyl-L-lysine and $N \alpha$-acetyl-L-ornithine using lysyl oxidase activity from the egg shell membrane following the procedure

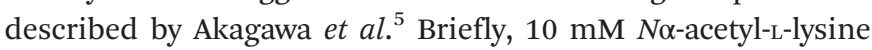
and $N \alpha$-acetyl-L-ornithine were independently incubated with constant stirring with $5 \mathrm{~g}$ egg shell membrane in $50 \mathrm{~mL}$ of $20 \mathrm{mM}$ sodium phosphate buffer, $\mathrm{pH} 9.0$ at $37^{\circ} \mathrm{C}$ for $24 \mathrm{~h}$. The egg shell membrane was then removed by centrifugation and the $\mathrm{pH}$ of the solution was adjusted to $6.0 \mathrm{using} 1 \mathrm{M} \mathrm{HCl}$. The resulting aldehydes were reductively aminated with $3 \mathrm{mmol}$ ABA in the presence of $4.5 \mathrm{mmol} \mathrm{NaBH}_{3} \mathrm{CN}$ at $37^{\circ} \mathrm{C}$ for $2 \mathrm{~h}$ with stirring. Then, ABA derivatives were hydrolyzed by $50 \mathrm{~mL}$ of $12 \mathrm{M} \mathrm{HCl}$ at $110{ }^{\circ} \mathrm{C}$ for $10 \mathrm{~h}$. The hydrolysates were evaporated at $40{ }^{\circ} \mathrm{C}$ in vacuo to dryness using a Savant speed-vac concentrator. The resulting AAS-ABA and GGS-ABA were purified by using silica gel column chromatography and ethyl acetate/acetic acid/water $(20: 2: 1, \mathrm{v} / \mathrm{v} / \mathrm{v})$ as the elution solvent. The purity of the resulting solution and authenticity of the standard compounds obtained following the aforementioned procedures have been checked by using MS and ${ }^{1} \mathrm{H}$ NMR.

\subsection{Analysis of AAS and GGS}

A $200 \mu \mathrm{L}$ sample of the experimental units was dispensed in $2 \mathrm{~mL}$ screw-capped Eppendorf tubes and treated with $1 \mathrm{ml}$ of cold 10\% TCA solution. Each Eppendorf was vortexed and then proteins were precipitated with centrifugation at $5000 \mathrm{~g}$ for $5 \mathrm{~min}$ at $4{ }^{\circ} \mathrm{C}$. The supernatant was removed, and the resulting pellet was treated again with $1.5 \mathrm{~mL}$ of cold $5 \%$ TCA solution. A new centrifugation was performed at $5000 \mathrm{~g}$ for $5 \mathrm{~min}$ at $4{ }^{\circ} \mathrm{C}$ for protein precipitation. The supernatant was removed, and then the pellets were treated with the following freshly prepared solutions: $0.5 \mathrm{~mL}$ of $250 \mathrm{mM}$ MES buffer $\mathrm{pH}$ 6.0 containing $1 \%$ SDS and $1 \mathrm{mM}$ DTPA, $0.5 \mathrm{~mL}$ of $50 \mathrm{mM}$ ABA in $250 \mathrm{mM}$ MES buffer $\mathrm{pH} 6.0$, and $0.25 \mathrm{~mL}$ of $100 \mathrm{mM}$ $\mathrm{NaBH}_{3} \mathrm{CN}$ in $250 \mathrm{mM}$ MES buffer $\mathrm{pH}$ 6.0. The derivatization was completed by allowing the mixture to react at $37^{\circ} \mathrm{C}$ for $90 \mathrm{~min}$. The samples were stirred every $30 \mathrm{~min}$. The derivatization was stopped by adding $0.5 \mathrm{~mL}$ of cold $50 \%$ TCA followed by centrifugation at $5000 \mathrm{~g}$ for $5 \mathrm{~min}$. The pellet was then washed twice with $10 \%$ TCA and diethyl ether-ethanol $(1: 1)$. Centrifugations at $5000 \mathrm{~g}$ for $10 \mathrm{~min}$ were performed after each washing step. The pellet was treated with $6 \mathrm{~N} \mathrm{HCl}$ and kept in an oven at $110{ }^{\circ} \mathrm{C}$ for $18 \mathrm{~h}$ until completion of hydrolysis. The hydrolysates were dried in vacuo using a Savant speed-vac concentrator. Finally, the generated residue was reconstituted with $200 \mu \mathrm{L}$ of Milli-Q water and then filtered through hydrophilic polypropylene GH Polypro (GHP) syringe filters $(0.45 \mu \mathrm{m}$ pore size, Pall Corporation) for HPLC analysis.

Samples were eluted in a Cosmosil 5C18-AR-II RP-HPLC column $(5 \mu \mathrm{m}, 150 \mathrm{~mm} \times 4.6 \mathrm{~mm})$ equipped with a guard column $(10 \mathrm{~mm} \times 4.6 \mathrm{~mm})$ packed with the same material (Nacalai Inc., USA). A Shimadzu 'Prominence' HPLC apparatus (Shimadzu Corp., Kyoto, Japan), equipped with a quaternary solvent delivery system (LC-20AD), a DGU-20AS online degasser, a SIL-20A autosampler, a RF-10A XL fluorescence detector, and a CBM-20A system controller, was used. Sodium acetate buffer (50 mM, pH 5.4) (eluent A) and acetonitrile (ACN) (eluent B) were used as eluents. A low-pressure gradient programme was used, varying $\mathrm{B}$ concentration from $0 \%$ (min 0$)$ to $8 \%(\min 20)$. The volume injection was $0.5 \mu \mathrm{L}$, the flow rate was kept at $1 \mathrm{~mL} \mathrm{~min}^{-1}$, and the temperature of the column was maintained constant at $30{ }^{\circ} \mathrm{C}$. Excitation and emission wavelengths were set at 283 and $350 \mathrm{~nm}$, respectively. Standards $(0.2 \mu \mathrm{L})$ were run and analyzed under the same conditions. Identification of both derivatized semialdehydes in the FLD chromatograms was carried out by comparing their retention times with those from the standard compounds. The peaks corresponding to AAS-ABA and GGS-ABA were manually 
integrated from FLD chromatograms and the resulting areas were plotted against an ABA standard curve with known concentrations that ranged from 0.1 to $0.5 \mathrm{mM}$. Results are expressed as nmol of carbonyl compound per $\mathrm{mg}$ of protein.

\section{Statistics}

All experimental units were prepared in triplicate and each individual sample at each sampling time was analyzed three times for each measurement. The effect of the addition of the tea catechins on the extent of Trp loss and the formation of AGEs and protein carbonyls was analyzed by an Analysis of Variance (ANOVA). The Tukey's test was used for multiple comparisons of the means. The significance level was set at $P<0.05$.

\section{Results and discussion}

\subsection{Binding affinity between catechins and human plasma proteins}

The binding affinities of catechins (EGCG, EC, EGC, Fig. 1) for HSA and $\mathrm{HH}$ were assessed by the ability of these phytochemicals to quench the intrinsic fluorescence of Trp. The fluorescence intensity of the experimental units containing HSA and $\mathrm{HH}$ gradually decreased with increasing concentrations of all tested tea catechins. The fluorescence quenching data were computed for calculating the bimolecular quenching constants $\left(K_{\mathrm{q}}\right)$ and the binding constants $\left(K_{\mathrm{b}}\right)$ of EC, EGC and EGCG associated with each of the human plasma proteins under study. As reported in Table 1 , the $K_{\mathrm{q}}$ values in all tested systems are higher than the diffusion-controlled rate constant of the biomolecules $\left(K_{\text {diff }}=1.0 \times 10^{10} \mathrm{~L} \mathrm{~mol}^{-1} \mathrm{~s}^{-1}\right)$ which confirmed that the static quenching mechanism of the catechins is the main reason behind the loss of intrinsic protein fluorescence. The chemistry of this interaction usually involves the reaction of the hydroxyl group with the carboxyl residues of the protein to form hydrogen bonds. As a result of this reaction, the di-hydroxyl moiety of a polyphenol is readily oxidized to an orthoquinone, and then the quinine forms a dimer in a side reaction, or reacts with amino or sulfhydryl side chains of polypeptides to form covalent $\mathrm{C} \backslash \mathrm{N}$ or $\mathrm{C} \backslash \mathrm{S}$ bonds with the phenolic ring, with the regeneration of the hydroquinone. ${ }^{20}$ This molecular interaction may alter the microenvironment of the Trp-214 residue in HSA and the Trp-37 residue in the $\beta$-subunit in $\mathrm{HH}$ which have been reported to be responsible for the fluorescence emitted by both human plasma proteins. $^{21}$

Regarding the differences between experimental units, the highest quenching rate constant in HSA solutions was found for EGCG $\left(15.30 \times 10^{12} \mathrm{M}^{-1} \mathrm{~s}^{-1}\right)$ followed by EC $(3.51 \times$ $\left.10^{12} \mathrm{M}^{-1} \mathrm{~s}^{-1}\right)$ and EGC $\left(1.43 \times 10^{12} \mathrm{M}^{-1} \mathrm{~s}^{-1}\right)$. Consistently, the strongest binding affinity for the same complexes followed the decreasing order $5.81 \times 10^{4} \mathrm{~L} \mathrm{~mol}^{-1}, 1.40 \times 10^{4} \mathrm{~L} \mathrm{~mol}^{-1}$ and $0.60 \times 10^{4} \mathrm{~L} \mathrm{~mol}^{-1}$, for EGCG, EC and EGC respectively. These<smiles>Oc1cc(O)c2c(c1)O[C@H](c1ccc(O)c(O)c1)[C@H](O)C2</smiles><smiles>Oc1cc(O)c2c(c1)O[C@H](c1cc(O)c(O)c(O)c1)[C@H](O)C2</smiles>

EGC<smiles>O=C(O[C@H]1Cc2c(O)cc(O)cc2O[C@@H]1c1cc(O)c(O)c(O)c1)c1cc(O)c(O)c(O)c1</smiles>

EGCG

Fig. 1 Structures of the catechins tested in the present study. EC: (-)-epicatechin; EGC: (-)-epigallocatechin; EGCG: (-)-epigallocatechin3-gallate.

Table 1 The bimolecular quenching rate constants $\left(K_{\mathrm{q}} ; \times 10^{12} \mathrm{M}^{-1} \mathrm{~s}^{-1}\right)$ and binding constants $\left(K_{\mathrm{b}} ; \times 10^{4} \mathrm{~L} \mathrm{~mol}^{-1}\right)$ between the catechins species and the serum human proteins tested

\begin{tabular}{|c|c|c|c|c|}
\hline & \multicolumn{2}{|l|}{ HSA } & \multicolumn{2}{|l|}{$\mathrm{HH}$} \\
\hline & $K_{\mathrm{q}}$ & $K_{\mathrm{b}}$ & $K_{\mathrm{q}}$ & $K_{\mathrm{b}}$ \\
\hline EC & 3.51 & 1.40 & 1.02 & 0.37 \\
\hline EGC & 1.43 & 0.60 & 0.58 & 0.24 \\
\hline EGCG & 15.30 & 5.81 & 3.63 & 1.53 \\
\hline
\end{tabular}


values are comparable with those reported by Trnková et al. ${ }^{17}$ who analyzed the interaction mechanisms between these phytochemicals and HSA using a similar spectroscopic approach. The structural properties of the tea polyphenols largely explain the binding affinities of these phytochemicals for plasma proteins. $^{20,22}$ In particular, the hydroxyl groups are known to play a key role in these interactions as hydroxylation of phenolic rings leads to an increase of the binding sites. ${ }^{22}$ The higher ability of EGCG to bind to both human plasma proteins may be explained by the presence of the galloyl moiety on the C-ring of this catechin. ${ }^{22}$ In addition, the catechin with a catechol group on the B-ring (EC) had a stronger binding affinity than the species with a pyrogallol group (EGC). ${ }^{20}$ By applying an HPLC analysis with an immobilized HSA column, Ishii et $a{ }^{16}{ }^{16}$ studied the binding affinities of green tea catechins for HSA and reported that the most important structural element contributing to the HSA binding of tea catechins is the galloyl group, followed by the number of hydroxyl groups on the B-ring and the galloyl group or the configuration at C-2. Applying Fourier Transform Infrared (FTIR) methodologies and docking studies, Maiti et al. ${ }^{23}$ provided substantial insight into the molecular interaction between EGCG and HSA. In addition to the confirmed strong affinity between both molecules, the authors also reported that van der Waals interactions and hydrogen bonding are primarily responsible for the overall negative $-G^{\circ}$ of the reaction and also that the red shift in the fluorescence spectra of HSA in the presence of EGCG (also observed in the present study) is due to an increased polar environment in the Trp-214 residue in HSA.

While the quenching rate constants between the catechins and $\mathrm{HH}$ followed a similar order with EGCG $\left(3.63 \times 10^{12} \mathrm{M}^{-1}\right.$ $\left.\mathrm{s}^{-1}\right)$ showing the highest quenching potential followed by EC $\left(1.02 \times 10^{12} \mathrm{M}^{-1} \mathrm{~s}^{-1}\right)$ and EGC $\left(0.58 \times 10^{12} \mathrm{M}^{-1} \mathrm{~s}^{-1}\right)$ the values were lower as compared to those found for HSA. The binging affinities of the catechins for $\mathrm{HH}$ were in good agreement with their quenching abilities $\left(1.53 \times 10^{4} \mathrm{~L} \mathrm{~mol}^{-1}, 0.37 \times 10^{4} \mathrm{~L}\right.$ $\mathrm{mol}^{-1}, 0.24 \times 10^{4} \mathrm{~L} \mathrm{~mol}^{-1}$, for EGCG, EC and EGC, respectively). The differences in binding affinities of catechins for different proteins could be explained by several factors, including their hydrophobicity, isoelectric point and amino acid composition. ${ }^{24} \mathrm{HH}$ has been much less studied than HSA for its molecular interactions with polyphenols. According to a study carried out by Xiao et $a .^{25}$ in bovine hemoglobin (BH), the affinities of flavonoids for this protein increased with an increasing partition coefficient which meant that the binding interaction between polyphenols and $\mathrm{BH}$ was mainly caused by hydrophobic forces. $\mathrm{BH}$ as well as $\mathrm{HH}$ is a highly polar macromolecule consisting of large numbers of amino, hydroxyl, and carboxylic residues. The results from the present study and the differences in binding affinities between tea catechins and $\mathrm{HH}$ are in general consistent with the data reported by Xiao et al. $^{25}$ for $\mathrm{BH}$.

Unlike the aforementioned studies, the concentration range of the tea catechins in the present experimental units was adjusted to that reported to occur in the plasma of human individuals after tea consumption. ${ }^{14,15}$ Hence, the present results confirm the intense affinity and molecular interactions between human plasma proteins and these three species under conditions closer to a realistic physiological situation.

The reactions between polyphenols and plasma proteins have attracted great interest owing to the consequences of such interactions. Binding polyphenols not only affect the structure and conformation of HSA as demonstrated by Maiti et $a l . ;^{23}$ the functionality of the protein and relevant physiological processes may also be affected. For instance, the distribution, metabolism, and efficacy of many drugs are correlated with their affinities toward both HSA and HH. In the present study, the consequences of these molecular interactions were further investigated for the radical scavenging activity of both the proteins and the catechins and the potential protection of the latter against the glucosemediated carbonylation of the former.

\subsection{In vitro antioxidant activity of catechins and human proteins}

Table 2 shows the values of percent inhibition against DPPH of the experimental units containing each of the tea catechins and human proteins alone, and the combination of them ( 2 proteins $\times 3$ tea catechins). The three catechins displayed, at the tested concentrations, a radical scavenging capacity against DPPH that ranged between 13.95 and 18.85\%. These results are in general concurrence with that obtained by Nanjo et $a .^{26}$ who reported that tea catechins and their epimers showed $50 \%$ radical scavenging ability in the concentration range of 1 to $3 \mu \mathrm{M}$. However, the differences found among catechins for their antiradical activity diverge from those reported by previous researchers who stated that the antioxidant activity of tea was mainly attributed to the esterified catechins (EGCG/ECG). ${ }^{26,27}$ Using Electron Spin Resonance (ESR) measurements, Guo et $a .^{27}$ confirmed that the presence of a gallate group at the 3 position played the most important role in their abilities to scavenge free radicals. They also reported that the scavenging capacity of EGC was higher than that of EC, suggesting that the presence of a hydroxyl group at the $5^{\prime}$ position also played an important role in their ability to scavenge free radicals. It is worth mentioning that

Table 2 Percent inhibition against the DPPH radical of HSA, HH $(20 \mathrm{mg}$ $\left.\mathrm{mL}^{-1}\right)$, EC $(0.7 \mu \mathrm{M}), \mathrm{EGC}(1.8 \mu \mathrm{M})$, and EGCG $(0.7 \mu \mathrm{M})$ and the combination of all of them

\begin{tabular}{|c|c|c|c|}
\hline & \multirow{2}{*}{$\frac{19.92^{\mathrm{x}, \mathrm{a}} \pm 0.10}{\mathrm{HSA}}$} & \multirow{2}{*}{$\frac{17.38^{\mathrm{y}, \mathrm{a}} \pm 0.12}{\mathrm{HH}}$} \\
\hline & & & \\
\hline $18.85^{\mathrm{x}, \mathrm{a}} \pm 0.10$ & EC & $18.05^{\mathrm{y}, \mathrm{c}} \pm 0.10$ & $17.38^{\mathrm{z}, \mathrm{a}} \pm 0.19$ \\
\hline $13.95^{\mathrm{z}, \mathrm{c}} \pm 0.18$ & EGC & $18.48^{\mathrm{x}, \mathrm{b}} \pm 0.12$ & $17.01^{\mathrm{y}, \mathrm{b}} \pm 0.13$ \\
\hline $14.44^{\mathrm{x}, \mathrm{b}} \pm 0.26$ & EGCG & $12.09^{\mathrm{d}, \mathrm{z}} \pm 0.11$ & $13.10^{\mathrm{c}, \mathrm{y}} \pm 0.11$ \\
\hline
\end{tabular}


the concentration of the catechins as well as the ratio of catechin/DPPH is considerably lower in the present study compared to the aforementioned work and this factor is highly influential in the outcome of this in vitro assay. ${ }^{28}$ The bulky steric hindrance of catechins containing galloyl groups has been reported to obstruct their DPPH scavenging activities ${ }^{27}$ and this condition may have played a major role at lower concentrations of the catechins used in this study.

On the other hand, both human plasma proteins displayed antioxidant capacity against DPPH and this capacity was comparable with that shown by the tea catechins (Table 2). Though the scavenging activity of $\mathrm{HH}$ was in the range of all biomolecules tested, it was significantly lower than that of HSA. The antioxidant properties of HSA are well-documented and considered to be responsible for several important physiological and pharmacological functions. ${ }^{29}$ The two sulfur-containing residues in HSA, Met and Cys, have been reported to account for $40-80 \%$ of the total antioxidant activity of the protein and more than $70 \%$ of the free radical-trapping activity in serum. ${ }^{30}$ Again, the antioxidant capacity of $\mathrm{HH}$ is less documented than that of HSA while recent reports identified the $\beta 93$ cysteine residue as a major contributor of its radicalscavenging property and a relevant element of vascular antiinflammatory defense. ${ }^{31}$

The radical scavenging activities of the experimental units combining catechins and human plasma proteins were lower than the activities displayed by the individual elements (Table 2). This finding may indicate that the polyphenolprotein molecular interactions inhibit the antioxidant capacity of the whole system (Table 2). The binding affinity of the catechins for the human proteins seemed to play a role in the antioxidant capacity of the experimental units with both biomolecules. The scavenging activity of EGCG and EC decreased in the presence of HSA and $\mathrm{HH}$ while the activity of EGC, which showed a lower binding affinity for the proteins, increased. Cao et $a .^{32}$ also found that the DPPH scavenging percentages of polyphenols decreased with increasing affinities for bovine serum albumin (BSA). On the one hand, the scavenging activity of plasma proteins, highly dependent on the free thiols, may be lost as a result of the nucleophilic addition of such protein residues with quinones. ${ }^{33}$ The depletion of free thiols is a common consequence of the covalent binding of phenolics to protein residues. ${ }^{34}$ Bae et al. ${ }^{35}$ reported that the incubation of EGCG with HSA occurred along with the loss on a free sulfhydryl group in HSA which supports the present hypothesis. As already explained, the nucleophilic addition leads to the regeneration of the hydroquinone which may display antioxidant properties due to the presence of hydroxyl groups. ${ }^{20}$ While, according to the present results, the antioxidant potential of the protein-bound catechin may be lower than that of the free catechin, the former may exert efficient protection against the radicalmediated oxidation of neighboring protein residues. Almajano et $a l .{ }^{36}$ came to similar conclusions while testing the radical scavenging of adducts formed by EGCG and assorted plasma and dairy proteins.

\subsection{In vitro glycation of HSA and $\mathrm{HH}$ : tryptophan depletion and formation of carbonyls and AGEs}

The chemical modifications induced in HSA and $\mathrm{HH}$ as a result of the incubation (10 days per $37^{\circ} \mathrm{C}$ ) with glucose $(12 \mathrm{mM})$ and iron $(0.2 \mathrm{mM})$ are depicted in Fig. 2 . The glycation of HSA has been typically linked to Maillard-mediated mechanisms that proceed via the attachment of a glucose molecule to $\mathrm{N}$-terminal residues or the $\varepsilon$-amino group of protein-bound lysine residues, resulting in the formation of reversible Schiff bases. These adducts are in equilibrium with the glucose in solution and with their rearranged Amadori products that may subsequently undergo irreversible rearrangement to form fluorescent AGEs. ${ }^{7}$ However, glucose can actually undergo metal-catalyzed oxidation that leads to the production of ketoaldehydes, hydrogen peroxide and other highly reactive
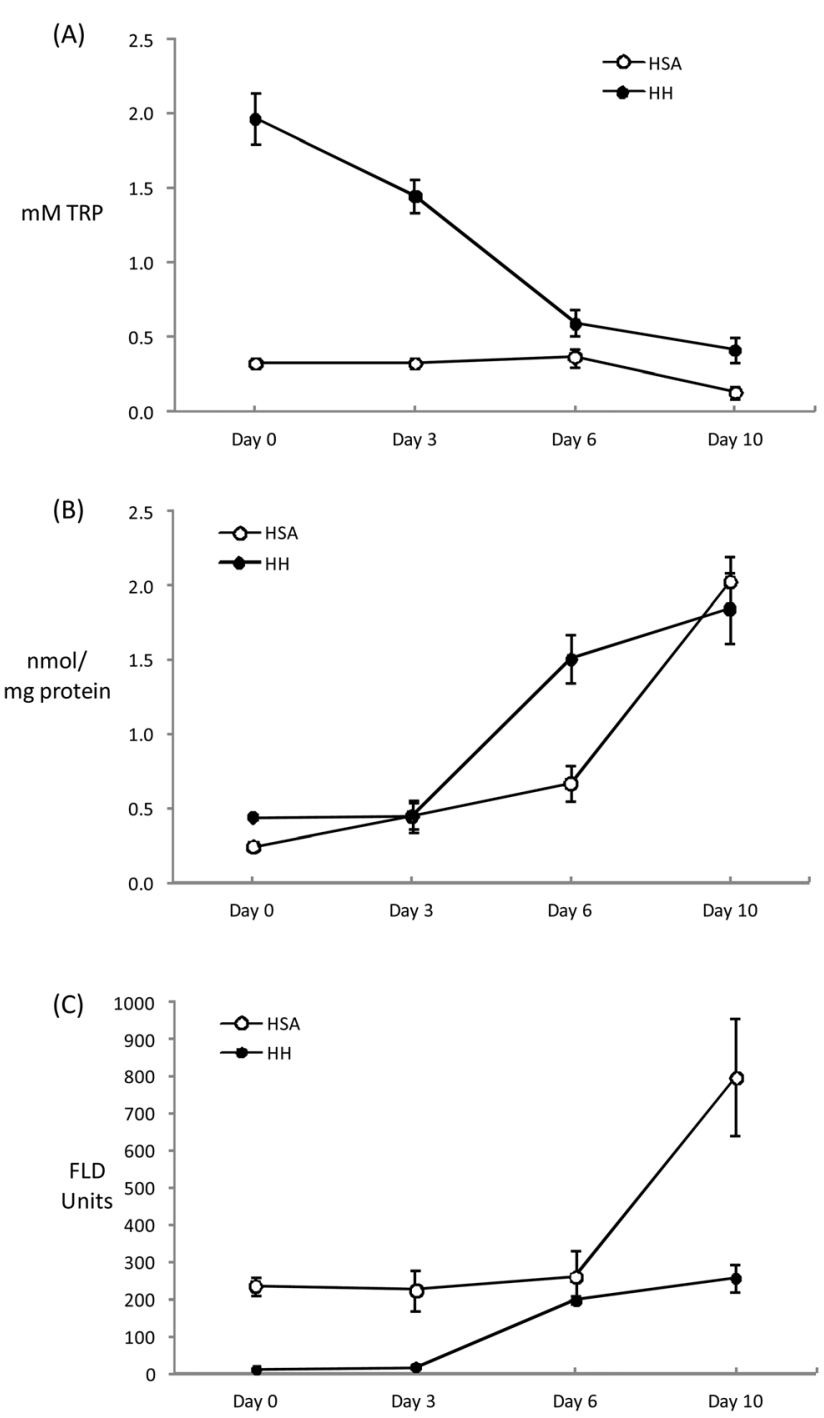

Fig. 2 Evolution of TRP concentration (A), carbonyl content (B) and pentosidine fluorescence $(C)$ during incubation of $\mathrm{HSA}$ and $\mathrm{HH}$ solutions (20 mg mL ${ }^{-1}$ ) for 10 days at $37^{\circ} \mathrm{C}$ with glucose $(12 \mathrm{mM})$ and iron $(0.2 \mathrm{mM})$. 
oxidants. ${ }^{8}$ Furthermore, Hedegaard et al. ${ }^{37}$ recently reported the formation of reactive oxygen species during the incubation of $\beta$-lactoglobulin with glucose $(1 \mathrm{M})$ and $\mathrm{Fe}^{2+}(5 \mathrm{mM})$ and the subsequent radical-mediated oxidation of the protein. While the experimental conditions of this latter experiment are considerably severe, simulated physiological conditions like those applied in the present study have also been found to generate reactive carbonyls and ROS from glucose autoxidation. ${ }^{8}$ Hence, the chemical damage to the present human plasma proteins could be reasonably attributed to the pro-oxidant action of species formed from 'autoxidative glycosylation' reactions.

Tryptophan is highly sensitive to ROS and its depletion is considered an early expression of the oxidative damage to proteins. The initial Trp concentrations in HH and HSA solutions decreased throughout the incubation assay with this depletion being more remarkable in $\mathrm{HH}$ due to the initial larger concentration of this amino acid (Fig. 2A). At the end of the assay, HSA and HH lose 63 and $80 \%$ of the initial Trp, respectively. Similar Trp depletions were recorded by Khan et al. ${ }^{38}$ inducing an in vitro glycation of HSA for up to 20 weeks in the absence of metals. The metal-catalyzed oxidation of glucose may definitely accelerate the loss of Trp as Coussons et al. ${ }^{39}$ observed a dramatic Trp loss in HSA when $\mathrm{Cu}^{2+}(50 \mu \mathrm{M})$ was added to the glucose-induced (5-50 $\mathrm{mM}$ ) glycation assay. In the absence of the metal, the loss of Trp was negligible even at high glucose concentrations $(500 \mathrm{mM})$ and prolonged incubation periods at $37^{\circ} \mathrm{C}$ (56 days). It can be hypothesized whether the decrease in the fluorescence of the tryptophanyl residues was caused by a glycation-dependent conformational change within the protein that affected the local environment of Trp. However, whenever pro-oxidative species are present (i.e. glucose is combined with transition metals) the loss of Trp is promoted plausibly via free radical mechanisms. ${ }^{8}$ The present results illustrate the high susceptibility of $\mathrm{HH}$ to glucose-mediated degradation as previously reported by Cussimanio et al. ${ }^{40} \operatorname{Trp}$ is particularly susceptible as glycated $\mathrm{HH}$ has been found to undergo structural modifications leading to an exposure of Trp residues ${ }^{41}$ that may be readily oxidized by glucose-mediated ROS. This is a relevant finding owing to the biological significance of Trp oxidation in a hyperglycemic environment. ${ }^{42}$ The recurrent observation of low Trp levels in the plasma of diabetic patients may be caused by the molecular mechanisms described here and this may lead to further disorders such as enzyme malfunction and neurological complications. ${ }^{43}$

The formation of specific carbonyls, AAS and GGS, occurred in both plasma proteins during incubation (Fig. 2B). After 10 days, the concentration of carbonyls significantly increased from 0.24 to 2.03 in HSA and from 0.44 to $1.85 \mathrm{nmol} \mathrm{mg}^{-1}$ protein in HH. The carbonylation of human plasma proteins under hyperglycemic conditions, including that which occurred in diabetic patients, has been profusely documented. ${ }^{10,38,41,44}$ However, this analysis is commonly made using unspecific methods for the detection of protein hydrazones upon DNPH derivatization while the exact nature of the carbonyl species as well as the underlying chemical pathways were not described. In fact, to the best of our knowledge, this study reports original data on the concentration of AAS and GGS in human plasma proteins incubated under simulated physiological conditions. Before us, only Akagawa et al. ${ }^{9}$ reported elevated levels of both protein carbonyls in diabetic rats. The same authors ${ }^{5}$ proved the in vitro formation of these semialdehydes in BSA in the presence of glucose-derived $\alpha$-dicarbonyls (2 mM glyoxal and methylglyoxal), confirming the occurrence of 'autoxidative glycosylation' mechanisms in the oxidative damage to glycated proteins. The Maillard-mediated mechanism has been thoroughly described elsewhere. ${ }^{5,6}$ These highly reactive dicarbonyls may condense with the e-amino group from the side chains of lysine, arginine and proline causing oxidative deamination and the subsequent formation of the carbonyl moiety in the side chain of the susceptible amino acid. Taking into consideration the proven generation of ROS as a result of the metal-catalyzed oxidation of glucose, the formation of AAS and GGS via a direct attack of free radicals on alkaline amino acids could plausibly have happened. In fact, the formation of both carbonyls in plasma and muscle proteins has been induced in vitro by hydroxyl-radical generating systems. ${ }^{5,45}$ Hence, protein glycation and protein oxidation are inextricably linked as two different pathways lead to the formation of the same product and under the conditions of the present experiment, the contribution of each mechanism to carbonyl formation is indistinguishable.

The concentration of carbonyls (AAS + GGS) in HSA and HH after 10 days of incubation at $37^{\circ} \mathrm{C}$ in the presence of glucose $(12 \mathrm{mM})$ and $\mathrm{Fe}^{3+}(200 \mu \mathrm{M})$ in the present study, is in the range reported by Akagawa et al. ${ }^{5}$ in BSA and in line with the extent of protein carbonylation found in diabetic patients. ${ }^{10,46,47}$ Both proteins behaved similarly in their susceptibility to carbonylation though $\mathrm{HH}$ suffered a more intense damage at an intermediate sampling (day 6) (Fig. 2B). Carbonylation may have progressed faster in this protein owing to the reported effect of glycosylation on the release of heme iron from $\mathrm{HH}$ that enhances, in turn, further oxidative damage including Trp depletion and carbonylation. ${ }^{44}$ The carbonylation level was similar between proteins at the end of the assay as a likely consequence of the total consumption of glucose (data not shown), that could have acted as a limiting factor.

Finally, and as expected, the incubation of human proteins with glucose and $\mathrm{Fe}^{3+}$ led to an increase in pentosidine (Fig. 2C). This AGE is a potent protein-crosslinking agent typically formed in glycosylation reactions between proteins and reducing sugars. Using specific anti-radical agents, Khan et $a l .{ }^{38}$ were able to block the formation of pentosidine in HSA treated with $0.05 \mathrm{M}$ glucose, incriminating the hydroxyl and superoxide radicals in pentosidine formation. The behavior of the plasma proteins in the present study is consistent with that reported previously. ${ }^{38-40}$ The pentosidine specific fluorescence was more intense in HSA and the increase observed during the last stage of incubation enlarged the differences between proteins. This remarkable difference between HSA and $\mathrm{HH}$ may be due to the presence and availability of lysine and arginine residues on the surface of the protein as both amino acids are involved in pentosidine formation. 
Pentosidine is used as a marker of diseases and commonly used as an indicator of diabetes complications such as hypertension, heart failure and retinopathy. ${ }^{48}$

\subsection{Effect of catechins against human protein glycation}

Owing to the close connection between glycosylation and oxidative stress in hyperglycemia and diabetes, diverse plant materials with antioxidant potential have recently been tested as natural remedies for alleviating the symptoms of the metabolic syndrome. ${ }^{11,44,49}$ In most of these studies, however, the chemistry behind the interaction of the phytochemicals in particular biomolecules remains unknown. In particular, the understanding of the impact of these catechins on the oxidative stability of human proteins is critical owing to the biological significance of protein oxidation in these metabolic disorders. The ability of tea catechins at postprandial concentrations in plasma to inhibit the glucose-mediated oxidative damage to human plasma proteins was assessed and the results are displayed in Fig. 3-5.

Catechins fully inhibited Trp degradation as the concentration of Trp in the experimental units treated with the catechins did not vary during incubation $(p>0.05)$ (data not shown). The effectiveness of the catechins against Trp oxidation, as assessed by the remaining Trp, was similar in the experimental units with HSA (Fig. 3A) while significant

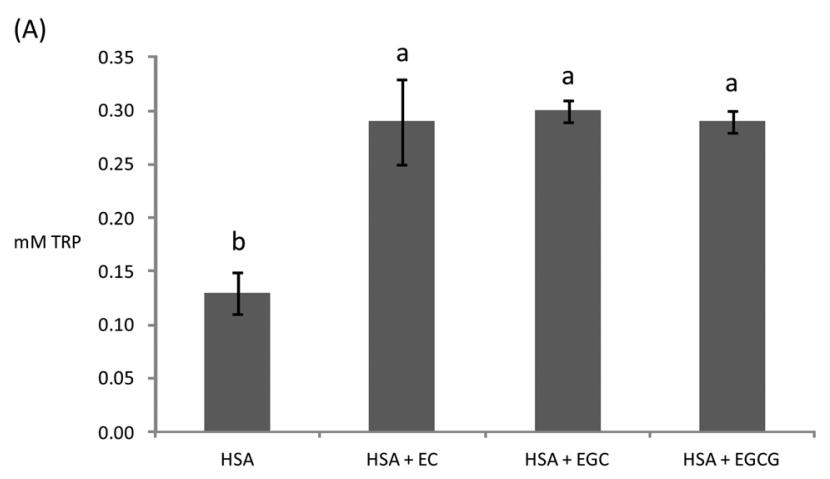

(B)

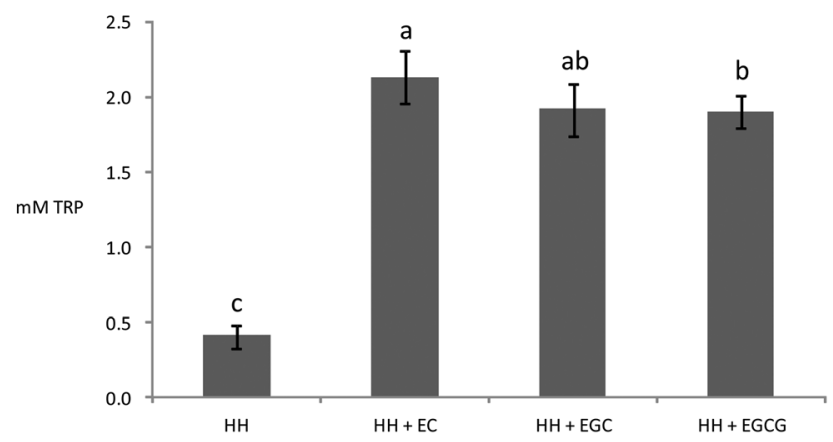

Fig. 3 Remaining Trp concentration in HSA (A) and $\mathrm{HH}$ (B) solutions (20 mg mL ${ }^{-1}$ ) after incubation for 10 days at $37^{\circ} \mathrm{C}$ with glucose $(12 \mathrm{mM}$ ), iron $(0.2 \mathrm{mM})$ and, when denoted, with EC $(0.7 \mu \mathrm{M})$, EGC $(1.8 \mu \mathrm{M})$, and EGCG $(0.7 \mu M) .{ }^{a, b, c}$ Different letters on the top of bars denote significant differences between treatments.
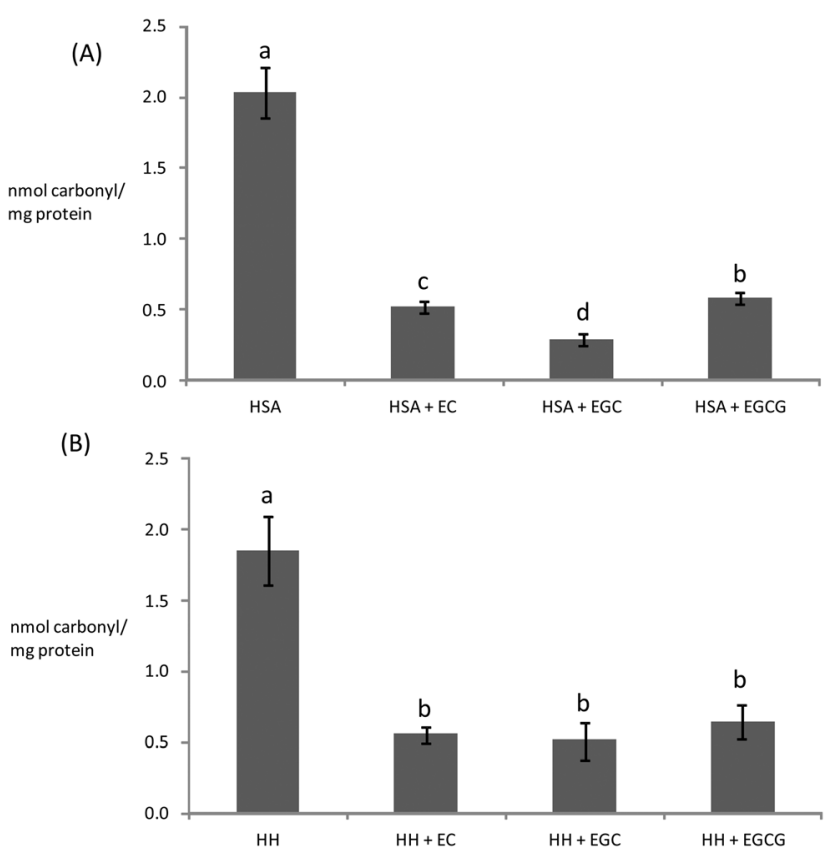

Fig. 4 Concentration of carbonyls (AAS + GGS) in HSA (A) and HH (B) solutions $\left(20 \mathrm{mg} \mathrm{mL}^{-1}\right.$ ) incubated for 10 days at $37^{\circ} \mathrm{C}$ with glucose $(12 \mathrm{mM})$, iron $(0.2 \mathrm{mM})$ and, when denoted, with $\mathrm{EC}(0.7 \mu \mathrm{M}), \mathrm{EGC}$ $(1.8 \mu \mathrm{M})$, and EGCG $(0.7 \mu \mathrm{M}){ }^{\mathrm{a}, \mathrm{b}, \mathrm{c}}$ Different letters on the top of bars denote significant differences between treatments.

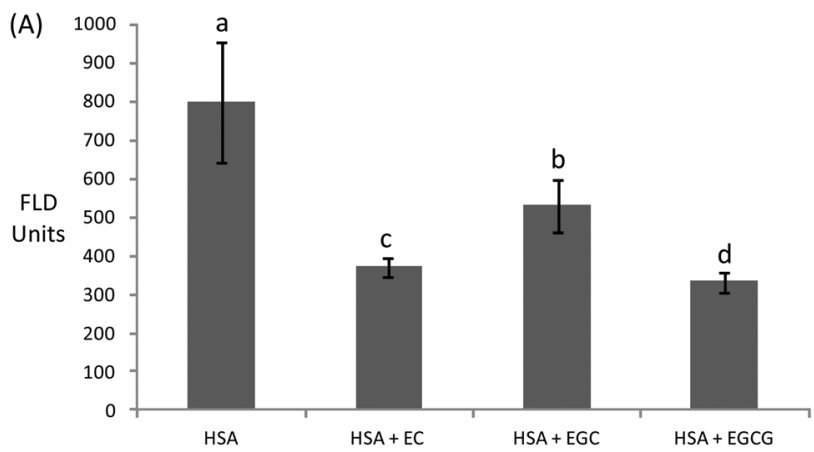

(B)

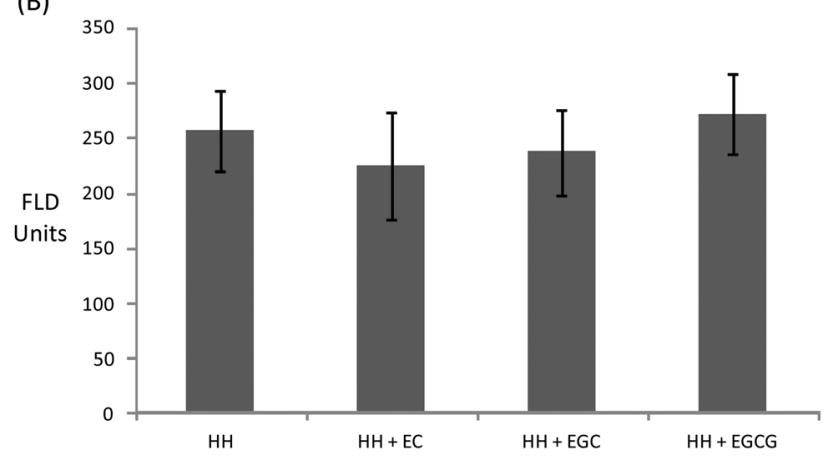

Fig. 5 Pentosidine fluorescence in HSA (A) and HH (B) solutions (20 mg $\mathrm{mL}^{-1}$ ) incubated for 10 days at $37{ }^{\circ} \mathrm{C}$ with glucose $(12 \mathrm{mM})$, iron $(0.2 \mathrm{mM})$ and, when denoted, with EC $(0.7 \mu \mathrm{M})$, EGC $(1.8 \mu \mathrm{M})$, and EGCG $(0.7 \mu M) .{ }^{a, b, c}$ Different letters on the top of bars denote significant differences between treatments. 
differences were found in $\mathrm{HH}$ (Fig. 3B). HH solutions with EC had a significantly higher remaining Trp than solutions containing EGCG while EGC was in an intermediate position. Catechins also protected plasma proteins against glucosemediated carbonylation (Fig. 4). While the three catechins under study reduced the protein carbonyls in $\mathrm{HH}$ to a similar extent (Fig. 4B), significant differences were found between catechins in their ability to control carbonylation of HSA (Fig. 4A). EGC displayed more intense protection against HSA carbonylation followed by EC and EGCG. Anyway, the percent inhibitions against HSA carbonylation were beyond the $80 \%$ for the three catechins. The protection of the tested catechins against the glycation of $\mathrm{HH}$ was not reflected in the formation of pentosidine (Fig. 5). Compared to HH, HSA suffered a more intense pentosidine formation and in this case a significant protective effect of catechins was observed and followed the decreasing order EGCG > EC > EGC (Fig. 5A).

The antioxidant activity of catechins is generally attributed to their ability to chelate metals and scavenge free radicals ${ }^{26}$ with any of these two mechanisms being applicable to the present results. The protection of catechins on plasma proteins has been previously documented, including both oxidative (radical-mediated) and glycosylative stress. ${ }^{50}$ However, the outstanding ability of the three catechins at such low plasmatic concentrations to inhibit Trp oxidation and AAS/GGS formation in $\mathrm{HH}$ and HSA has no precedent in the literature.

The results obtained for the effect of catechins on carbonylation and pentosidine suggest a likely connection between the affinity of the phytochemicals to bind to the proteins and their ability to protect against the glucose-mediated oxidative damage. The effect of catechins against carbonylation was inversely related to their ability to bind to proteins, which suggests a more intense activity of the free species. In contrast, binding to the protein seemed to be linked to the ability to protect against pentosidine formation. This is reasonable as in addition to their antioxidant activities, attached phenolics may exert some steric hindrance to the formation of cross-links between intra- or intermolecular protein residues. The fact that such effects were only observed in HSA, for which catechins had a higher affinity, provides some strength to this hypothesis.

The present results provide an approximate picture of the beneficial effects that tea consumption may have against the glycosylation of HSA and $\mathrm{HH}$ at a pathological glucose concentration $(\sim 12 \mathrm{mM})$. It is worth noting that physiological studies report the presence of both free and conjugated forms of the three catechins in the bloodstream upon tea consumption. ${ }^{14,15}$ The protective effects reported in the present study may only be applicable to the free forms. The consequences of this protection are of biological significance since the oxidative degradation of plasma proteins reflects the damage that oxidative stress may cause in living cells and tissues. ${ }^{3}$ Glycation-modified hemoglobin in particular, has been suggested to be a source of enhanced catalytic iron and free radicals causing pathological complications in diabetes mellitus. ${ }^{44}$ On this line, Roy et $a l .{ }^{44}$ found that dietary pelargonidin protected against glucose-mediated $\mathrm{HH}$ oxidation leading to an overall amelioration of oxidative stress linked to hyperglycemia. Regarding specific molecular changes, the loss of Trp and the formation of carbonyls in particular, have been found to play a role in the pathogenesis of diabetes, the metabolic syndrome and other disorders caused by oxidative stress. ${ }^{3}$ Chetyrkin et $a .^{42}$ originally reported on the relationship between the oxidation of tryptophan and the altered function of proteins under hyperglycemic conditions. In response to this relevant finding, Jain ${ }^{43}$ hypothesized (i) whether this would explain the reduced plasmatic levels of Trp in Type II diabetic patients and (ii) if this impairment may be neutralized by inhibitors of glycol-oxidative reactions. As long as the present results could be confirmed in an in vivo system, catechins may provide means to alleviate plasmatic Trp depletion under hyperglycemic conditions and hence, control the serious consequences linked to such a disorder. ${ }^{42}$ Protein carbonyls and pentosidine, on the other side, have been recurrently described as stable markers of multiple metabolic disorders including Type II diabetes. $^{3}$ Interestingly, a recent report ${ }^{51}$ highlighted $\alpha$-amino adipic acid (AAA), the oxidation end-product of AAS, as the most reliable early indicator of diabetes risk in humans. The authors also found that AAA could modulate the function of endocrine pancreas and induce diabetes in experimental animals fed the aforementioned compound. As long as lysine oxidation/glycation products play a role as signaling molecules or are even involved in the pathogenesis of metabolic disorders, tea catechins may contribute to normalizing a homeostatic situation by inhibiting carbonylation of plasma proteins.

\section{Conclusion}

Protein carbonyls (AAS and GGS) may be used as reliable and specific markers of the oxidative damage caused to human plasma proteins under hyperglycemic conditions. The trp depletion reported in plasma from diabetic patients may be explained by the molecular mechanisms reported in the present paper. Three major tea catechins were able to efficiently inhibit the oxidative damage to human hemoglobin and HSA at postprandial blood concentrations. It is of note that an impaired oxidative status is thought to be responsible for the metabolic syndrome and further health complications in diabetic patients. These results emphasize the beneficial effects of tea catechins against the impairment of glucose metabolism in human individuals. The present results provide scientific evidence for the control of the oxidative stress linked to hyperglycemia through dietary tea catechins.

\section{Abbreviation}

HSA Human serum albumin

$\mathrm{HH} \quad$ Human hemoglobin

BSA Bovine serum albumin 
EC (-)-Epicatechin

EGC (-)-Epigallocatechin

EGCG (-)-Epigallocatechin-3-gallate

Trp Tryptophan

AAA $\quad \alpha$-Aminoadipic acid

AAS $\quad \alpha$-Aminoadipic semialdehyde

GGS $\gamma$-Glutamic semialdehyde

AGEs Advanced glycation end products

\section{References}

1 E. R. Stadtman and B. S. Berlett, Reactive oxygen-mediated protein oxidation in aging and disease, Chem. Res. Toxicol., 1997, 10, 485-494.

2 O. P. Soladoye, M. L. Juarez, J. L. Aalhus, P. Shand and M. Estévez, Protein oxidation in processed meat: Mechanisms and potential implications on human health, Compr. Rev. Food Sci. Food Saf., 2015, 14, 106-122.

3 I. Dalle-Donne, D. Giustarini, R. Colombo, R. Rossi and A. Milzani, Protein carbonylation in human diseases, Trends Mol. Med., 2003, 9, 169-176.

4 M. Estévez, Protein carbonyls in meat systems: A review, Meat Sci., 2011, 89, 259-279.

5 M. Akagawa, D. Sasaki, Y. Kurota and K. Suyama, Formation of $\alpha$-aminoadipic and $\gamma$-glutamic semialdehydes in proteins by the Maillard reaction, Ann. N. Y. Acad. Sci., 2005, 1043, 129-134.

6 A. Villaverde and M. Estévez, Carbonylation of myofibrillar proteins through the maillard pathway: Effect of reducing sugars and reaction temperature, J. Agric. Food Chem., 2013, 61, 3140-3147.

7 N. Shaklai, R. L. Garlick and H. F. Bunn, Nonenzymatic glycosylation of human serum albumin alters its conformation and function, J. Biol. Chem., 1984, 259, 3812-3817.

8 S. P. Wolff, Z. Y. Jiang and J. V. Hunt, Protein glycation and oxidative stress in diabetes mellitus and ageing, Free Radical Biol. Med., 1991, 10, 339-352.

9 M. Akagawa, T. Sasaki and K. Suyama, Oxidative deamination of lysine residue in plasma protein of diabetic rats. Novel mechanism via the Maillard reaction, Eur. J. Biochem., 2002, 269, 5451-5458.

10 P. Odetti, S. Garibaldi, G. Noberasco, I. Aragno, S. Valentini, N. Traverso and U. M. Marinari, Levels of carbonyl groups in plasma proteins of Type 2 diabetes mellitus subjects, Acta Diabetol., 1999, 36, 179-183.

11 A. Scalbert, C. Manach, C. Morand, C. Rémésy and L. Jiménez, Dietary polyphenols and the prevention of diseases, Crit. Rev. Food Sci. Nutr., 2005, 45, 287-306.

12 Y. Wang and C.-T. Ho, Polyphenols chemistry of tea and coffee: A century of progress, J. Agric. Food Chem., 2009, 57, 8109-8114.

13 S. H. Guo, E. Bezard and B. L. Zhao, Protective effect of green tea polyphenols on the SH-SY5Y cells against 6-OHDA induced apoptosis through ROS-NO pathway, Free Radical Biol. Med., 2005, 39, 682-695.
14 C. S. Yang, L. Chen, M.-J. Lee, D. Balentine, M. C. Kuo and S. P. Schantz, Blood and urine levels of tea catechins after ingestion of different amounts of green tea by human volunteers, Cancer Epidemiol. Biomarkers Prev., 1998, 7, 351-354.

15 M.-J. Lee, P. Maliakal, L. Chen, X. Meng, F. Y. Bondoc, S. Prabhu, G. Lambert, S. Mohr and C. S. Yang, Pharmacokinetics of tea catechins after ingestion of green tea and (-)-epigallocatechin-3-gallate by humans: Formation of different metabolites and individual variability, Cancer Epidemiol. Biomarkers Prev., 2002, 11, 1025-1032.

16 T. Ishii, K. Minoda, M.-J. Bae, T. Mori, Y. Uekusa, T. Ichikawa, Y. Aihara, T. Furuta, T. Wakimoto, T. Kan and T. Nakayama, Binding affinity of tea catechins for HSA: Characterization by high-performance affinity chromatography with immobilized albumin column, Mol. Nutr. Food Res., 2010, 54, 816-822.

17 L. Trnková, I. Boušová, V. Staňková and J. Dršata, Study on the interaction of catechins with human serum albumin using spectroscopic and electrophoretic techniques, J. Mol. Struct., 2011, 985, 243-250.

18 J. R. Lakowicz, Principles of Fluorescence Spectroscopy, Kluwer Academic/Plenum Press, New York, 1999, Ch. 8 and 13.

19 S. Bi, L. Ding, Y. Tian, D. Song, X. Zhou, X. Liu and $\mathrm{H}$. Zhang, Investigation of the interaction between flavonoids and human serum albumin, J. Mol. Struct., 2004, 307, 37-45.

20 T. Ozdal, E. Capanoglu and F. Altay, A review on proteinphenolic interactions and associated changes, Food Res. Int., 2013, 51, 954-970.

21 M. Itoh, H. Mizukoshi, K. Fuke, S. Matsukawa, K. Mawatari, Y. Yoneyama, M. Sumitani and K. Yoshihara, Tryptophan fluorescence of human hemoglobin. I. Significant change of fluorescence intensity and lifetimes in the $\mathrm{T}-\mathrm{R}$ transition, Biochem. Biophys. Res. Commun., 1981, 100, 1259-1265.

22 J. Xiao, F. Mao, F. Yang, Y. Zhao, C. Zhang and K. Yamamoto, Interaction of dietary polyphenols with bovine milk proteins: molecular structure-affinity relationship and influencing bioactivity aspects, Mol. Nutr. Food Res., 2011, 55, 1637-1645.

23 T. K. Maiti, K. S. Ghosh and S. Dasgupta, Interaction of (-)-epigallocatechin-3-gallate with human serum albumin: Fluorescence, Fourier transform infrared, circular dichroism, and docking studies, Proteins, 2006, 64, 355-362.

24 S. V. E. Prigent, H. Gruppen, A. J. W. G. Visser, G. A. H. D. Van Koningsveld and G. J. V. Alfons, Effects of noncovalent interactionswith 5-o-caffeoylquinic acid (CGA) on the heat denaturation and solubility of globular proteins, J. Agric. Food Chem., 2003, 51, 5088-5095.

25 J. B. Xiao, J. L. Huo, F. Yang and X. Q. Chen, Noncovalent interaction of dietary polyphenols with bovine hemoglobin in vitro: Molecular structure/property-affinity relationship aspects, J. Agric. Food Chem., 2011, 59, 8484-8490.

26 F. Nanjo, K. Goto, R. Seto, M. Suzuki, M. Sakai and Y. Hara, Scavenging effects of tea catechins and their derivatives on 1,1- diphenyl-2-picrylhdrazyl radical, Free Radical Biol. Med., 1996, 21, 895-902. 
27 Q. Guo, B. Zhao, S. Shen, J. Hou, J. Hu and W. Xin, ESR study on the structure-antioxidant activity relationship of tea catechins and their epimers, Biochim. Biophys. Acta, 1999, 1427, 13-23.

28 A. M. Osman, Multiple pathways of the reaction of 2,2-diphenyl-1-picrylhydrazyl radical (DPPH) with (+)-catechin: Evidence for the formation of a covalent adduct between DPPH and the oxidized form of the polyphenols, Biochem. Biophys. Res. Commun., 2011, 412, 473478.

29 M. Taverna, A.-L. Marie, J.-P. Mira and B. Guidet, Specific antioxidant properties of human serum albumin, Ann. Intensive Care, 2013, 3, 1-7.

30 E. Bourdon, N. Loreau, L. Lagrost and D. Blache, Differential effects of cysteine and methionine residues in the antioxidant activity of human serum albumin, Free Radical Res., 2005, 39, 15-20.

31 D. A. Vitturi, et al., Antioxidant functions for the hemoglobin $\beta 93$ cysteine residue in erythrocytes and in the vascular compartment in vivo, Free Radical Biol. Med., 2013, 55, 119-129.

32 H. Cao, X. Chen and K. Yamamoto, Bovine serum albumin significantly improves the DPPH free radical scavenging potential of dietary polyphenols and gallic acids, AntiCancer Agents Med. Chem., 2012, 12, 940-948.

33 W. S. Pierpoint, o-Quinones formed in plant extracts. Their reaction with bovine serum albumin, Biochem. J., 1969, 112, 619-629.

34 S. Jongberg, M. N. Lund and J. Otte, Dissociation and reduction of covalent $\beta$-lactoglobulin-quinone adducts by dithiothreitol, tris(2-carboxyethyl)phosphine, or sodium sulfite, Anal. Biochem., 2015, 478, 40-48.

35 M.-J. Bae, T. Ishii, K. Minoda, Y. Kawada, T. Ichikawa, T. Mori, M. Kamihira and T. Nakayama, Albumin stabilizes (-)-epigallocatechin gallate in human serum: Binding capacity and antioxidant property, Mol. Nutr. Food Res., 2009, 53, 709-715.

36 M. P. Almajano, M. E. Delgado and M. H. Gordon, Albumin causes a synergistic increase in the antioxidant activity of green tea catechins in oil-in-water emulsions, Food Chem., 2007, 102, 1375-1382.

37 R. V. Hedegaard, L. Liu and L. H. Skibsted, Quantification of radicals formed during heating of $\beta$-lactoglobulin with glucose in aqueous ethanol, Food Chem., 2015, 167, 185-190.

38 M. W. A. Khan, Z. Rasheed, W. A. Khan and R. Ali, Biochemical, biophysical, and thermodynamic analysis of in vitro glycated human serum albumin, Biochemistry, 2007, 72, 146-152.

39 P. J. Coussons, J. Jacoby, A. McKay, S. M. Kelly, N. C. Price and J. V. Hunt, Glucose modification of human serum albumin: A structural study, Free Radical Biol. Med., 1997, 22, 1217-1227.

40 B. L. Cussimanio, A. A. Booth, P. Todd, B. G. Hudson and R. G. Khalifah, Unusual susceptibility of heme proteins to damage by glucose during non-enzymatic glycation, Biophys. Chem., 2003, 105, 743-755.

41 S. Sen, M. Kar, A. Roy and A. S. Chakraborti, Effect of nonenzymatic glycation on functional and structural properties of hemoglobin, Biophys. Chem., 2005, 113, 289-298.

42 S. V. Chetyrkin, M. E. Mathis, A.-J. L. Ham, D. L. Hachey, B. G. Hudson and P. A. Voziyan, Propagation of protein glycation damage involves modification of tryptophan residues via reactive oxygen species: inhibition by pyridoxamin, Free Radical Biol. Med., 2008, 44, 1276-1285.

43 S. K. Jain, Can tryptophan oxidation lead to lower tryptophan level in diabetes? A commentary on "Propagation of protein glycation damage involves modification of tryptophan residues via reactive oxygen species: Inhibition by pyridoxamine", Free Radical Biol. Med., 2008, 44, 12731275.

44 M. Roy, S. Sen and A. S. Chakraborti, Action of pelargonidin on hyperglycemia and oxidative damage in diabetic rats: Implication for glycation-induced hemoglobin modification, Life Sci., 2008, 82, 1102-1110.

45 M. Estévez, V. Ollilainen and M. Heinonen, Analysis of protein oxidation markers - $\alpha$-aminoadipic and $\gamma$-glutamic semialdehydes - in food proteins by using LC-ESI-MultiStage Tandem MS, J. Agric. Food Chem., 2009, 57, 39013910.

46 U. Çakatay, Protein oxidation parameters in Type 2 diabetic patients with good and poor glycaemic control, Diabetes Metab., 2005, 31, 551-557.

47 G. Caimi, E. Hopps, D. Noto, B. Canino, M. Montana, D. Lucido, R. Lo Presti and M. R. Averna, Protein oxidation in a group of subjects with metabolic syndrome, Diabetes Metab. Syndr., 2013, 7, 38-41.

48 S. Sugiyama, et al., Plasma levels of pentosidine in diabetic patients: An advanced glycation end product, J. Am. Soc. Nephrol., 1998, 9, 1681-1688.

49 X.-X. Zheng, Y.-L. Xu, S.-H. Li, R. Hui, Y.-J. Wu and X.-H. Huang, Effects of green tea catechins with or without caffeine on glycemic control in adults: A meta-analysis of randomized controlled trials, Am. J. Clin. Nutr., 2013, 97, 750-762.

50 T. Nakagawa, T. Yokozawa, K. Terasawa, S. Shu and L. R. Juneja, Protective activity of green tea against free radical- and glucose-mediated protein damage, J. Agric. Food Chem., 2002, 50, 2418-2422.

51 T. J. Wang, et al., 2-Aminoadipic acid is a biomarker for diabetes risk, J. Clin. Invest., 2013, 23, 4309-4317. 